\title{
El aporte de la Teoría de la Economía Civil a la argumentación de la RSE
}

\section{Contributions from the Civil Economy Theory to the argumentation of CSR}

Oscar Daniel Licandro Goldaracena es Investigador y Coordinador del Programa de Investigación sobre RSE de la Universidad Católica del Uruguay (Uruguay) (olicandr@ucu.edu.uy) (https://orcid.org/0000-0002-7771-2933)

\begin{abstract}
Resumen
Pese a la creciente legitimidad que está adquiriendo la Responsabilidad Social Empresarial (RSE), la argumentación teórica de esa legitimidad presenta fuertes debilidades. Estas debilidades se explican, en parte, porque esa argumentación no está basada en un marco de teoría económica alternativo a la Economía Neoclásica, en cuyos postulados e ideas se apoyan las principales críticas a la existencia de la RSE. Para esta escuela el concepto de RSE entra en contradicción con ideas como la que el fin de la empresa consiste exclusivamente en la maximización de las ganancias, la esfera económica es independiente de la social, el mercado es moralmente neutro y que las relaciones económicas se basan exclusivamente en el intercambio de equivalentes sin dejar espacio para la reciprocidad. El presente artículo tiene la intención de argumentar que la escuela denominada «Economía Civil» aporta un marco teórico desde el cual es posible responder a esas críticas y ofrecer una argumentación de la RSE basada en esa teoría. El documento fue construido mediante revisión bibliográfica y reflexión teórica del autor. Se identifican cinco dimensiones que caracterizan el concepto de RSE, luego se analizan los argumentos neoclásicos que invalidan esas dimensiones y finalmente, se exponen los argumentos de la Economía Civil que los legitiman.
\end{abstract}

\begin{abstract}
In spite the growing legitimacy of Corporate Social Responsibility (CSR), its theoretical argumentation presents great weaknesses. These weaknesses are explained, in part, because the argument is not based on a framework of economic theory, alternative to Neoclassical Economics, whose postulates and ideas support the main criticisms of the existence of CSR. The concept of CSR contradicts ideas such as: the end of the company consists exclusively on maximizing profits, the economic sphere is independent of the social sphere, the market is morally neutral, and economic relations are based exclusively in equivalent exchange without allowing reciprocity. This article argues that the school of Civil Economy provides a theoretical framework from which it is possible to respond to these criticisms and offer an argument for CSR based on its theories. The document was constructed using a bibliographic review and theoretical reflection by the author. It identifies five dimensions that characterize the concept of CSR. It then analyzes the neoclassical arguments that invalidate those dimensions. Finally, it presents the arguments from Civil Economy that legitimize.
\end{abstract}

\section{Palabras clave I keywords}

Economía Civil, Economía Neoclásica, Responsabilidad Social Empresarial, stakeholder, externalidades, Ética. Civil Economy, Neoclassical Economy, Corporate Social Responsibility, stakeholder, externalities, ethics.

Cómo citar: Licandro Goldaracena, O.D. (2018). El aporte de la Teoría de la Economía Civil a la argumentación de la RSE. Retos Revista de Ciencias de la Administración y Economía, 8(16), 33-45. https://doi.org/10.17163/ret.n16.2018.03 


\section{Introducción}

Si bien la RSE posee actualmente un importante grado de legitimidad en el mundo corporativo y es un tema que ocupa un lugar relevante en la investigación académica, todavía existen fuertes críticas a este concepto que sus partidarios no han podido refutar en forma clara y contundente, en particular, las críticas que provienen de la escuela de Economía Neoclásica.

Si se analizan los documentos internacionales más importantes sobre RSE (como el Libro Verde de la Unión Europea, el Pacto Global de las Naciones Unidas o la guía ISO 26.000) y las diversas elaboraciones teóricas sobre este concepto, es posible concluir que en ellos no se propone una fundamentación de teoría económica de la RSE o, si se lo hace, esa fundamentación se formula en el marco de los conceptos centrales de la teoría neoclásica de la economía. Lo mismo ocurre si se analiza con detenimiento la forma como se abordan teóricamente los principales problemas que involucra este concepto: la gestión de las externalidades negativas de las empresas, la relación con los stakeholders, el comportamiento ético en los negocios, el involucramiento de la empresa en la solución de los problemas sociales o la creación de valor compartido. Es probable, además, que ello explique la supremacía de una fundamentación de tipo instrumental, en la que se propone la necesidad de la RSE como respuesta adaptativa de la empresa a un nuevo entorno o como estrategia pragmática e instrumental orientada a fines de rentabilidad, más que como una nueva visión filosófica -fundamentalmente de tipo moral- sobre el rol de la empresa en la sociedad.

El problema radica en que el concepto de RSE involucra un cuestionamiento profundo a la teoría económica dominante, aunque sus impulsores no sean conscientes de ello. Esta situación es la principal causa que explica la dificultad que tienen los impulsores de la RSE para refutar los argumentos en contra de esta filosofía de negocios, la mayoría de los cuales son formulados desde la perspectiva del pensamiento neoclásico de economía, donde destaca un célebre artículo de Milton Friedman (1970). Además, cabe destacar que a partir de la década de 1990 la producción académica sobre RSE prácticamente abandonó la reflexión teórica, para dar prioridad a la publicación de resultados de investigaciones empíricas, tal como lo señaló Carroll (1999), y como lo demuestra el hecho de que las nuevas definiciones sobre RSE propuestas en lo que va del siglo XX provienen de documentos institucionales, como el Libro Verde de la Unión Europea o la Guía ISO 26.000. Esta situación, que aún persiste, implicó una renuncia de facto a la discusión teórica sobre los fundamentos económicos de la RSE.

De ahí la necesidad de buscar un marco de teoría económica, basado en postulados diferentes a los neoclásicos, que sea consistente con el concepto de RSE. En este documento se argumenta que ese marco se encuentra en la escuela de pensamiento llamada «Economía Civil». El objetivo central de este documento es identificar y analizar los aportes de esta escuela a la fundamentación teórica de la RSE. El artículo identifica cinco dimensiones que componen el concepto moderno de RSE, analiza la inconsistencia lógica entre dichas dimensiones y los postulados del modelo neoclásico de economía y, finalmente, describe los elementos teóricos de la Economía Civil que dan un fundamento de teoría económica a esas dimensiones de la RSE. 


\section{Las dimensiones del concepto de RSE}

El análisis de la literatura (académica y no académica) sobre RSE, producido en el correr de los últimos sesenta años, pone de manifiesto la existencia una amplia diversidad de aportes sobre este tema y, particularmente, sobre la definición del concepto, tal como lo demuestran Carroll (1999), Garriga \& Melé (2004), Dahlsrud (2008) y Carroll (2015). En la segunda década del siglo XXI esa diversidad conceptual parece haber convergido en una definición que cuenta con amplios consensos, tanto a nivel académico como a nivel de los actores institucionales interesados en promover la RSE (por ejemplo: ONU, OCDE, Unión Europea). Ese consenso gira en torno a la definición y principales ideas que sobre la Responsabilidad Social se establecen en la Guía ISO 26.000, que la define como la «responsabilidad de una organización por los impactos de sus decisiones y actividades sobre la sociedad y el medioambiente, a través de un comportamiento trasparente y ético» (ISO, 2011, p.106). Además, se señala en este documento que la adopción de la RSE resulta de una elección voluntaria, se incorpora a toda la operación de la empresa y presupone el cumplimiento de las leyes locales e internacionales.

La revisión de la literatura sugiere que se trata de un concepto complejo y multidimensional, tal como lo evidencia el trabajo de Carroll (2015), quien analiza lo puntos en común y superposiciones entre la RSE y otros cinco conceptos: Teoría del Valor Compartido, Teoría de los Stakeholders, Ciudadanía Corporativa, Business Ethics y Sostenibilidad. La revisión de la literatura sobre RSE de los últimos sesenta años pone de relieve que este concepto incluye al menos cinco dimensiones: 1) la gestión responsable de los impactos (externalidades) de la actividad empresarial sobre los stakeholders, la sociedad y el medioambiente; 2) la incorporación de los intereses y demandas de los stakeholders y la creación de valor compartido con ellos; 3) actuar en forma ética; 4) involucrarse en la solución de los problemas sociales y ambientales de la comunidad donde la empresa opera y 5) contribuir al desarrollo sostenible

La gestión de los impactos de la operación productiva y comercial constituye el núcleo central de la definición de RSE propuesta en la Guía ISO 26.000. Davis \& Blomstronm (1966) sugirieron la idea de que las empresas deben considerar la forma como su actividad afecta a los demás actores. Fitch (1976) definió la RSE como el intento de resolver los problemas sociales que ellas generan. Frederick et al. (1992) propusieron que las empresas deben ser responsables de los efectos de cualquiera de sus acciones en su comunidad y el medio ambiente. La Unión Europea afirmó que para ejercer plenamente su responsabilidad social, la empresa debe «identificar, prevenir y atenuar sus posibles consecuencias adversas» (Commission of the European Communities, 2011, p.7). Más recientemente, Carroll (2015) observó que la gestión socialmente responsable de los impactos abarca dos dimensiones: por un lado, "proteger» a la sociedad de los impactos negativos y por otro, contribuir a «mejorar» las condiciones de la sociedad mediante impactos positivos deliberadamente buscados. De igual forma, Wymer \& Rundle-thiele (2017), afirman que la RSE es una noción mediante la cual las organizaciones asumen la responsabilidad del impacto de sus actividades en un amplio variedad de stakeholders.

Johnson (1971) afirmó que la empresa socialmente responsable equilibra los intereses de múltiples actores, entre los que incluyó a los empleados, los proveedores y las 
comunidades locales. Jones (1980, p. 59) asoció la RSE con la idea de que las empresas tienen obligaciones con sus stakeholders más allá de lo establecido en leyes y contratos. Evan \& Freeman (1993) propusieron que el auténtico fin de la empresa es servir de vehículo para coordinar los intereses de los stakeholders. En la misma línea argumental, Garriga y Melé (2004) sostuvieron que la RSE requiere equilibrar los intereses de los accionistas con los intereses legítimos de todos los stakeholders. A principios de la década de 2000 se comenzó a asociar el concepto de RSE a la idea de que la empresa, debe generar valor social y ambiental, además de hacerlo con el valor económico, a lo que se denominó enfoque de la «triple cuenta de resultados» (Triple Bottom Line) (Van Marrewijk, 2001; Comission of the European Communities, 2002). Porter \& Kramer (2011) propusieron el concepto de «valor compartido», que la Comission of the European Communities (2011) hizo suyo al indicar que la RSE implica que el fin de las empresas consiste es maximizar el valor compartido con los stakeholders y con la sociedad.

McGuire (1963) incluyó entre los componentes de la RSE el actuar con «justicia». Keith Davis (1967) sostuvo que la esencia de la RSE emana de la preocupación por las consecuencias éticas de acciones que pueden afectar los intereses de los demás. Zenisek (1979) propuso un modelo de responsabilidad social basado en la relación entre ética empresarial y las expectativas de la sociedad. Carroll (1991) sostuvo que la empresa socialmente responsable se esfuerza por obtener ganancias, actuar en forma ética y ser un buen ciudadano corporativo. Epstein (2006) señaló que la responsabilidad social y la ética abordan temas y preocupaciones estrechamente relacionadas e incluso superpuestas. Hopkings (1998) afirmó que la RSE se relaciona con tratar a los stakeholders en forma ética. WBCSD (2000) definió la RSE como el compromiso continuo de las empresas por actuar éticamente y contribuir al desarrollo económico. Según Carroll (2015), en la segunda década del siglo XXI el concepto de Business Ethics pasó a ser parte del concepto de RSE.

Eilbert \& Parket (1973) propusieron que la RSE es un compromiso de la empresa con la solución de diversos problemas sociales y ambientales, entre los que incluyeron la contaminación y la discriminación racial. Según Matten et al. (2003) las empresas deben involucrarse en la solución de esos problemas debido a las dificultades crecientes de los Estados para hacerlo. La definición de RSE propuesta en el Libro Verde de la Unión Europea establece que la RSE es la «integración voluntaria, por parte de las empresas, de las preocupaciones sociales y medioambientales en sus operaciones comerciales y sus relaciones con sus interlocutores»(Comisión Europea, 2001, p.7). Existe una amplia diversidad de propuestas teóricas sobre el compromiso empresarial con la solución de estos problemas, que van desde las meramente filantrópicas hasta las que involucran la actividad productiva y comercial de las empresas, como es el caso de los denominados «Negocios con la Base de la Pirámide» (Prahalad \& Hart, 2002).

La relación entre Desarrollo Sostenible y RSE comenzó a plantearse a fines de la década de 1990, pero tomó fuerza a partir de la publicación del Libro Verde de la Unión Europea, donde se hace un llamado a las empresas europeas a que tengan un sentido de responsabilidad social en relación a diversos temas, entre los que se incluye el desarrollo sostenible (Comisión de las Comunidades Europeas, 2001). El tema está presente en el Pacto Global de Naciones Unidas de 1999 y se expone más claramente en los Objetivos de Desarrollo Sostenible (ODS) propuestos recientemente por esta 
organización. WBCSD (1999) definió la RSE como el «compromiso de las empresas para contribuir al desarrollo económico sostenible trabajando con los empleados, sus familias, la comunidad local y la sociedad en general para mejorar su calidad de vida».

Existe además un consenso más o menos generalizado acerca de que la RSE se ubica en el nivel estratégico e inclusive de filosofía de negocios, habiéndose superado las primeras versiones del concepto que la confundían con la filantropía o la reducían a un conjunto de tácticas de marketing orientadas al fortalecimiento de la marca y la construcción de reputación corporativa. Es decir, la RSE comienza a ser considerada como una forma de entender la relación entre la empresa con sus stakeholders (clientes, empleados, proveedores, inversores, vecinos, etc.), la sociedad en general y el medioambiente. Como toda filosofía, la RSE se sustenta en principios, valores, un concepto del hombre (antropología) y su relación con los otros hombres y la naturaleza, así como en una idea sobre la relación entre economía y sociedad. Por lo tanto, detrás del discurso de la RSE es posible encontrar diversas convicciones sobre cada uno de esos temas. El problema radica en que la mayoría de los impulsores de estas ideas no son conscientes de estas implicaciones teóricas y filosóficas y, por lo tanto, ellas no están explicitadas en su discurso.

\section{Los postulados de la Escuela Neoclásica y la RSE}

La crítica neoclásica a la RSE se sustenta en un conjunto de supuestos y postulados que incluyen verdades pseudo-científicas y afirmaciones de carácter normativo, así como en sus respectivas inferencias lógicas. Estos supuestos y postulados invalidan las cinco dimensiones de la RSE antes identificadas, tal como se explica a continuación y se ilustra en la segunda columna de la tabla 1. Un texto clásico de Milton Friedman (1970), en el que sostiene que la única responsabilidad social de la empresa consiste en generar rentabilidad para sus accionistas con la única limitación del cumplimiento de la ley y el respeto a ciertas convenciones morales, parece haber marcado la agenda del debate sobre la legitimidad de la RSE..

Para Friedman (1970) es necesario separar los fines económicos de los fines sociales. Estos son propios de los empresarios en tanto personas y por lo tanto, las contribuciones a la sociedad deben hacerlas en forma individual y separada del negocio. La empresa tiene exclusivamente un fin económico y lo económico es independiente de los social. En línea con Friedman, Steinberg (2000) sostiene que la empresa no tiene como finalidad promover el bien público, lo cual entra en contradicción con buena parte de las dimensiones de la RSE. Por su parte, Peter (2004) señala que para el enfoque neoclásico la legitimación en la esfera del mercado es automática, lo cual derriba toda la argumentación de algunos partidarios de la RSE que sostienen que el comportamiento socialmente responsable y la incorporación de la ética son condición necesaria para generar dicha legitimación. Además, entre los postulados de esta escuela se encuentra la idea que establece que las relaciones económicas son impersonales y moralmente neutras, lo que está claramente en contradicción con la dimensión ética de la RSE.

En la medida que el fin de la empresa es maximizar las utilidades, las relaciones con los stakeholders se reducen a transacciones basadas exclusivamente en el principio del intercambio de equivalentes regido por el contrato. Según este principio, luego de acordado el contrato, las partes dejan de ser libres y lo único que tiene sentido es que cada 
una de ellas cumpla con lo que le corresponde, siendo ésta su única responsabilidad. Fácil es inferir que, si las relaciones económicas se reducen exclusivamente al intercambio de equivalentes, deja de tener sentido que la empresa tenga que minimizar externalidades o contemplar las expectativas de los stakeholders que no están incluidos en los contratos o las leyes. De ahí que toda argumentación de la RSE deba ir más allá del intercambio de equivalentes e introducir en la economía relaciones de reciprocidad entre las partes.

Tabla 1. Los postulados de la Economía Neoclásica y las dimensiones de la RSE

\begin{tabular}{|c|c|c|}
\hline Dimensiones de la RSE & $\begin{array}{c}\text { Postulados de la } \\
\text { Economía Neoclásica }\end{array}$ & $\begin{array}{l}\text { Postulado de la } \\
\text { Economía Civil }\end{array}$ \\
\hline $\begin{array}{l}\text { La empresa gestiona respon- } \\
\text { sablemente las externalida- } \\
\text { des negativas no prohibidas } \\
\text { por las leyes o los contratos }\end{array}$ & $\begin{array}{l}\text { El fin de la empresa es } \\
\text { maximizar las ganan- } \\
\text { cias de los accionistas. } \\
\text { Los únicos límites a } \\
\text { cumplir este fin son los } \\
\text { que establecen las leyes } \\
\text { y los contratos }\end{array}$ & $\begin{array}{l}\text { El accionar de la empresa } \\
\text { se encuentra limitado por } \\
\text { sus fines y por la natura- } \\
\text { leza relacional del ser hu- } \\
\text { mano }\end{array}$ \\
\hline $\begin{array}{l}\text { La empresa considera los in- } \\
\text { tereses de los stakeholders y } \\
\text { crea valor compartido (triple } \\
\text { cuenta de resultados) }\end{array}$ & $\begin{array}{l}\text { La empresa considera } \\
\text { exclusivamente los inte- } \\
\text { reses de los accionistas. } \\
\text { Las relaciones económi- } \\
\text { cas se reducen al inter- } \\
\text { cambio de equivalentes }\end{array}$ & $\begin{array}{l}\text { El fin de la empresa es } \\
\text { satisfacer necesidades de } \\
\text { todos los actores involu- } \\
\text { crados. El intercambio } \\
\text { de equivalentes se puede } \\
\text { complementar con rela- } \\
\text { ciones de reciprocidad }\end{array}$ \\
\hline $\begin{array}{l}\text { La empresa incorpora las } \\
\text { consideraciones éticas en la } \\
\text { toma de decisiones }\end{array}$ & $\begin{array}{l}\text { El mercado es moral- } \\
\text { mente neutro. La em- } \\
\text { presa no necesita jus- } \\
\text { tificar éticamente sus } \\
\text { decisiones. }\end{array}$ & $\begin{array}{l}\text { El mercado no es moral- } \\
\text { mente neutro. La empresa } \\
\text { es éticamente responsable } \\
\text { de las consecuencias de su } \\
\text { actividad sobre los demás } \\
\text { actores. }\end{array}$ \\
\hline $\begin{array}{l}\text { La empresa incorpora a la } \\
\text { gestión consideraciones so- } \\
\text { ciales y ambientales }\end{array}$ & $\begin{array}{l}\text { Lo económico y lo so- } \\
\text { cial son independientes. } \\
\text { La empresa se ocupa ex- } \\
\text { clusivamente de aspec- } \\
\text { tos económicos. }\end{array}$ & $\begin{array}{l}\text { La dimensión económica } \\
\text { y la social están indisolu- } \\
\text { blemente ligadas por la } \\
\text { relacionalidad del sujeto } \\
\text { económico. La empresa es } \\
\text { social y tiene un compro- } \\
\text { miso con la sociedad en la } \\
\text { que opera. }\end{array}$ \\
\hline $\begin{array}{l}\text { La empresa se compromete } \\
\text { con el Desarrollo Sostenible }\end{array}$ & $\begin{array}{l}\text { La empresa únicamente } \\
\text { se ocupa de los bienes } \\
\text { privados }\end{array}$ & $\begin{array}{l}\text { La empresa tiene un rol } \\
\text { a cumplir en relación al } \\
\text { Bien Común }\end{array}$ \\
\hline
\end{tabular}

También el pensamiento neoclásico postula que la esfera económica es independiente de la social y que el único ámbito de actuación de la empresa es el de la economía. La empresa como institución persigue únicamente fines económicos. De ahí que, en el marco de la perspectiva neoclásica, conceptos como los de «valor social», 
«valor compartido» o «triple cuenta de resultados» sean contradictorios con la lógica del funcionamiento de los mercados y, por tanto, contrarios a los fines de la empresa. En consecuencia, no resulta válida la dimensión de la RSE relativa a incorporar consideraciones sociales y ambientales a la gestión empresarial. Y, particularmente, todo lo relativo a la contribución de la empresa al desarrollo sostenible, la participación activa en las comunidades, la lucha contra la pobreza, la protección de los Derechos Humanos y el cuidado del medioambiente.

Otro postulado implícito del pensamiento neoclásico afirma que la economía -y, por tanto, la empresa- se ocupa exclusivamente de los bienes privados, dejando para el Estado y la sociedad la gestión de los bienes públicos (res publica) y los bienes comunes (commons). Este supuesto refuerza la oposición a la idea de responsabilidad ambiental, ya que ésta involucra una especial consideración de los impactos empresariales sobre los bienes comunes (como el agua, el aire o el desarrollo sostenible) o los bienes públicos (como la infraestructura de las comunidades).

Todo lo anterior converge en la afirmación de que la RSE es un asunto privado de los empresarios y managers y que, en consecuencia, en caso de querer practicarla, ellos deben utilizar sus recursos personales y no los de la empresa. Si bien detrás de esta afirmación se encuentra un reduccionismo de la RSE a la filantropía social, su formulación implica un cuestionamiento directo a una idea central del concepto de RSE: la que establece que ella no es algo periférico al negocio.

\section{El aporte de la teoría de la Economía Civil a la fundamentación de la RSE}

\subsection{La Economía Civil}

La «Escuela de la Economía Civil» (Zamagni 2006, 2009, 2012) propone una solución al problema. Sus supuestos antropológicos y sus postulados sobre la relación entre empresa y sociedad, así como su propuesta sobre el fin último de la empresa, aportan un marco conceptual sólido para fundamentar la RSE, sin tener que recurrir a sofisticados argumentos que la lógica destruye fácilmente. Esta escuela sostiene una teoría de tipo normativo - ergo moral-, que propone un modelo de economía y un tipo de relaciones sociales bajo los cuales la persona puede desplegar su esencia y desarrollar su potencial relacional. Esta escuela se rebela contra las posturas deterministas que condenan a la humanidad a vivir en sociedades que atentan contra la relacionalidad de la persona, tanto las que sostienen que el hombre es un ser esencialmente competitivo, movido por el afán de maximizar su placer (las filosofías individualistas), como las que lo convierten en pieza de una maquinaria, estableciendo que el fin de su vida es estar al servicio de esa maquinaria (el marxismo y demás filosofías de tipo colectivista). Mientras que las teorías individualistas y colectivistas no explicitan sus postulados antropológicos y los revisten de verdades pseudo-científicas, la «Economía Civil», no sólo los explicita, sino que además los utiliza en forma expresamente transparente para fundamentar el desarrollo de su teoría.

La Economía Civil refuta el supuesto antropológico egoista que está en la base del andamiaje neoclásico y postula la hipótesis del hombre relacional. Esta escuela, que hunde su raíces en el pensamiento del filósofo y economista italiano del siglo XVIII 
Antonio Genovesi (Bruni \& Grevin, 2016), postula que para existir, prosperar y ser felices, los seres humanos necesitamos de los otros, tanto en nuestra vida personal como en nuestras actividades sociales y económicas. Según Zamagni (2012):

La tesis según la cual la prosocialidad y la reciprocidad son excepciones que se explican a la luz de la "preponderancia natural e histórica» del «interés propio» parece tan extrema como la tesis contraria. En su extraordinaria complejidad de comportamiento, el hombre puede guiarse por una gran variedad de motivaciones (p. 39).

No obstante su base normativa, la «Economía Civil» no consiste simplemente en un andamiaje conceptual, inferido de supuestos antropológicos y que prescinde de la contrastación con la realidad. Diversas investigaciones sobre el comportamiento humano avalan la hipótesis relacional y refutan la individualista (Zamagni, 2006; Hoevel 2009; Crivelli, 2003; Axelrod, 1984; Fehr \& Gachner, 2000). Estas investigaciones demuestran que bajo determinadas condiciones contextuales, los seres humanos priorizan la cooperación por sobre la competencia maximizadora de los intereses individuales. Dicho de otra forma, la «Economía Civil» propone -en sentido normativo, como algo bueno a ser perseguido- un tipo de economía (la economía civil de mercado), bajo la cual es posible el desarrollo de una sociedad -instituciones, formas de relación y convivencia- en la que los seres humanos pueden vivir en forma consistente con su esencia (como seres relacionales) y, además, demuestra empíricamente que esa economía es posible.

Tanto el enfoque individualista como el relacional se basan en visiones normativas (el deber ser) y en creencias acerca de cómo funciona el mundo real. Es decir, tanto los neoclásicos como los economistas civiles creen que el hombre actúa o tiende actuar en forma consistente con su postulado antropológico. Y también, ambos, encuentran evidencia empírica que sostiene esa convicción. Por un lado, el comportamiento atrozmente competitivo y depredador de muchos empresarios parece validar empíricamente el postulado antropológico individualista. Pero, por otro, las múltiples experiencias de trabajo colaborativo en el mundo de los negocios hacen lo propio con el postulado antropológico relacional. Ahora bien, mientras que este postulado no sostiene que las personas «siempre» actúan en forma cooperativa -lo que propone es que existe en ellas el potencial para hacerlo-, el postulado individualista asume que el hombre tiende a maximizar su placer, y que esto ocurre «siempre» en sus relaciones económicas.

\subsection{Una fundamentación de la RSE basada en los postulados de la Economía Civil}

Al invalidar el postulado antropológico del homo economicus, la Economía Civil también invalida los supuestos asociados con ella que refutan la RSE. A continuación se describe la forma cómo la hipótesis antropológica relacional aporta una fundamentación de cada una de las dimensione de la RSE. De esta forma, la «Economía Civil» ofrece a sus defensores un marco teórico para rebatir los argumentos que pretenden invalidarla. En la tercera columna de la tabla 1 se resumen estos argumentos.

Gestión responsable de las externalidades. El postulado relacional establece límites a la generación de externalidades negativas, ya que el daño que se genera a otros atenta contra la propia esencia humana. Bajo este postulado, e inversamente a lo que predica el enfoque neoclásico, lo moralmente correcto es minimizar las externalidades 
negativas más allá de las exigencias legales y contractuales. De modo que queda lógicamente validada la dimensión de la RSE relativa a la gestión responsable de los impactos.

Considerar los intereses de los stakeholders y construir valor compartido. La forma como los hombres abordan y practican sus actividades económicas está condicionada por su naturaleza relacional. En tanto construcción humana, la empresa es un instrumento al servicio del despliegue de esa relacionalidad. Bajo este supuesto la empresa tiene como fin principal la satisfacción de la necesidades materiales, emocionales y espirituales de las personas y de los grupos involucrados con ella (sus stakeholders), incluyendo a la sociedad en la que opera. El siguiente texto, extraído de la encíclica Centesimus Annus, legitima la idea de que la empresa responsable es aquella que construye valor compartido:

[...] la finalidad de la empresa no es simplemente la producción de beneficios, sino más bien la existencia misma de la empresa como comunidad de hombres que, de diversas maneras, buscan la satisfacción de sus necesidades fundamentales y constituyen un grupo particular al servicio de la sociedad entera (Juan Pablo II, 1998, p. 67).

La pretensión neoclásica de reducir las relaciones económicas exclusivamente a relaciones impersonales basadas en el contrato omite la esencia relacional del ser humano. Esta escuela propone que, al realizar su actividad, los empresarios dejan de lado la parte «no económica» de su naturaleza - el afecto, los valores personales, sus demás motivaciones, etc.- y por tanto, lo único que intercambian en esas relaciones son valores económicos equivalentes. Concebidas de esta forma, las relaciones económicas no dejan lugar a la confianza, al compromiso o al afecto. En cambio, asociada a su hipótesis antropológica, la «Economía Civil» sostiene que en las relaciones económicas las personas no pueden desdoblarse y omitir la dimensión de su naturaleza. Por esa razón, según esta teoría, en esas relaciones conviven el intercambio de equivalentes y la reciprocidad. El principio de reciprocidad es una de las principales categorías económicas de esta escuela de pensamiento (Groppa, 2014). La reciprocidad comienza con un acto de gratuidad de una de las partes -por ejemplo: dar un beneficio adicional a los trabajadores-, que busca desencadenar otro comportamiento de reciprocidad en quien lo recibe -por ejemplo: un mayor compromiso del trabajador con la empresa-. El supuesto que está detrás de esta propuesta establece que la reciprocidad permite generar círculos virtuosos que incrementan el beneficio de todas las partes. Es importante señalar que la «Economía Civil» no propone la reciprocidad como alternativa al intercambio de equivalentes. Por el contrario, lo que esta escuela sugiere a las empresas es que complementen las relaciones habituales y necesarias basadas en el principio de equivalencia, con comportamientos basados en la reciprocidad.

Incorporar la ética. También, para la «Economía Civil» el mercado no es una institución moralmente neutra. Lo que ocurre en él afecta la vida de las personas y ello conlleva una responsabilidad moral. La idea de la RSE como responsabilidad por los impactos de la actividad asigna un carácter moral al comportamiento empresarial. Según Zamagni (2012) el concepto de RSE presupone una «ética de la responsabilidad», no en el sentido que dio Max Weber a este concepto, sino la interpretación que de él se hace en la "Teoría de los stakeholders». De ahí que el comportamiento ético, basado en valores y en las competencias para resolver de la forma más justa posible los 
innumerables dilemas éticos a los que se enfrentan los directivos de las empresas, hace a la naturaleza de la empresa. Además, la «Economía Civil» postula la necesidad de una «ética de la virtud» en los directivos empresariales porque, según Zamagni (2012, p.198), este tipo de ética es la que permite «resolver y superar la contraposición entre el interés el interés por uno mismo y el interés por los demás; entre egoísmo y altruismo».

Involucrarse en los problemas sociales y ambientales. Tal como se mencionó, una de las críticas de la escuela Neoclásica a la RSE consiste en afirmar que la actividad económica opera en forma autónoma de las relaciones sociales. Como de ello se infiere que la empresa persigue únicamente fines económicos, no tiene sentido que se involucre en la solución de los problemas sociales. Más aún, hacerlo sería algo moralmente incorrecto, que podría llevar a su autodestrucción. De ahí que, en el marco de la perspectiva neoclásica, conceptos como el de "valor social», "valor compartido»o «triple cuenta de resultados» son contradictorios con la lógica del funcionamiento de los mercados y, en consecuencia, contrarios a los fines de la empresa. Desde la perspectiva de la «Economía Civil» se rebate este postulado, porque «lo económico y lo civil tienen en común la estructura relacional de la existencia humana» (Zamagni, 2006, p.18). Según Bruni \& Zamagni (2003, p.11), en los mercados globalizados actuales a «la empresa se le pide que sea social en la normalidad de su actividad económica». La «Economía Civil» postula la idea de que el fin de la empresa es social y que por lo tanto su compromiso es con toda la sociedad. Bajo este enfoque la RSE es parte de la naturaleza de la empresa y no algo que se agrega a su funcionamiento. Es por esa razón que Crespo (2009, p.121) afirma: «Sería más claro, entonces, hablar más que de RSE, de responsabilidad de la empresa en la sociedad».

Contribuir al desarrollo sostenible. El pensamiento neoclásico sostiene que la empresa debe ocuparse únicamente de los bienes privados. En este sentido, ella no debe hacerse responsable por los problemas ambientales ni por el desarrollo sostenible, ya que estos temas refieren a los bienes comunes (commons) y al Bien Común. Según Zamagni (2007, p. 23): «Es claro que en el horizonte del individualismo (axiológico) no haya lugar para la noción de bien común». Ahora bien, a nadie escapa que la producción descontrolada e irresponsable de bienes privados es una de las causas actuales de la crisis ambiental global -legitimada por el supuesto neoclásico de la validez de externalizar todo lo no prohibido por las leyes-. En este orden de ideas, los argumentos neoclásicos resultan legitimadores de las causas de esta crisis, y por lo tanto son incapaces de aportar un marco conceptual consistente con su solución. En cambio la «Economía Civil» propone un marco conceptual bajo el cual la empresa tiene un rol a desempeñar ante la crisis ambiental y la necesidad de un desarrollo sostenible, ya que su compromiso con el Bien Común deriva del postulado relacional, tal como argumenta Zamagni (2007):

El bien común, afirmando el primado de la relación interpersonal sobre su exoneración,...de la identidad personal sobre la utilidad, debe poder encontrar espacio de expresión por doquier, en cualquier ámbito del accionar humano, también comprendidas la economía y la política (p. 42). 


\section{Conclusiones}

Pese a ser un concepto que nace en el marco de la economía capitalista de mercado, la RSE posee muchos puntos de contacto con la «Economía Civil». Tal como se demostró en este documento, si se lee atentamente la definición propuesta en la guía ISO 26.000, se infiere de ella que el concepto de RSE se aproxima mucho más a la estructura conceptual de la «Economía Civil» que a la de la Escuela Neoclásica, proveedora del fundamento moral y teórico de la versión capitalista de la economía de mercado. Ésta es la razón por la que se sostiene en este artículo que la «Economía Civil» aporta los argumentos teóricos para rebatir las críticas de la escuela Neoclásica a la RSE.

En el marco de la economía capitalista de mercado, la RSE emerge como una filosofía de negocios que promueve la adopción de comportamientos alineados con la ética cívica propia de una economía civil de mercado. Sin pretender que la RSE modifique la esencia del sistema capitalista, la «Economía Civil» la percibe como una oportunidad para generar comportamientos económicos que rompan -aunque sea parcialmente- con las limitaciones que imponen las reglas del capitalismo. Dado que la evolución de la humanidad hacia una economía civil no está garantizada (porque la propuesta de la Economía Civil no es determinista), sus partidarios -entre quienes destaca la Iglesia Católica- adoptan la RSE como una filosofía de negocios que, en el marco de la economía capitalista de mercado, permite generar, dentro de restricciones específicas, comportamientos empresariales propios de la economía civil. El siguiente texto de Zamagni expresa en forma sintética esta idea:

Cuando todavía no existen instituciones civiles y justas o son incompletas, el bien común requiere algo más y algo diferente a la búsqueda correcta y honesta de los intereses particulares. Por eso, una empresa socialmente responsable es la que contribuye a definir la ética cívica... Actuar respetando las reglas dadas es demasiado poco, sobre todo cuando hay que cambiar esas reglas; es decir, cuando hay que superar la concepción calvinista del capitalismo [...] (Zamagni, 2012, p.187).

Dado que la empresa es una obra humana, creada y dirigida por personas, la adopción de la RSE como filosofía de negocios depende de la voluntad de quienes la dirigen. De ser cierto el postulado antropológico individualista, los empresarios y directivos de empresas propenderían a actuar en sentido contrario al que propone la RSE y ésta no dejaría de ser un linda utopía. Sin embargo, la «Economía Civil» argumenta la falsedad del postulado del homo economicus y de los principales supuestos del pensamiento neoclásico que invalidan la RSE: el fin de la empresa es exclusivamente la maximización de las ganancias, lo económico es independiente de lo social, el mercado es moralmente neutro, las relaciones económicas se basan exclusivamente en el intercambio de equivalentes, etc. De igual modo, la «Economía Civil» aporta a la RSE una fundamentación de antropología filosófica (la naturaleza relacional del ser humano) y de teoría económica, al tiempo que demuestra que, bajo determinadas circunstancias, los actores económicos buscan la cooperación y tienden a adoptar comportamientos como los que promueve la RSE. 


\section{Referencias}

Axelrod, R. (1984). The evolution of the Cooperation. New York: Basic Books.

Bruni, L., \& Zamagni, S. (2003). Persona y comunión: herramientas para una refundación relacional del discurso económico. En: Bruni, L., \& Zamagni, S. (Ed), Persona y comunión. Buenos Aires: Ciudad Nueva.

Bruni, L. \& Grevin, A. (2016). La Economía silenciosa. Economía de Comunión, empresas y capitalismo. Buenos Aires: Editorial Ciudad Nueva.

Carroll, A. (1991). The Pyramid of Corporate Social Responsibility: Toward the Moral Management of Organizational Stakeholders. Business Horizons, 34(4), 39-48. http://dx.doi.org/10.1016/0007-6813(91)90005-G

Carroll, A. (1999). Corporate Social Responsibility: Evolution of Definitional Construct. Business and Society, 38(3), 268-295. http://dx.doi.org/10.1177/000765039903800303

Carroll, A. (2015). Corporate social responsibility: The centerpiece of competing and complementary frameworks. Organizational Dynamics, 44(2), 87-96. https://doi.org/10.1016/j.orgdyn.2015.02.002

Comisión de las Comunidades Europeas (2001). Libro Verde: Fomentar un Marco Europeo para la Responsabilidad Social de las Empresas. COM (2001) 366 final. Bruselas: Comisión Europea. https:// goo.gl/KaN729 (22-06-2018).

Comisión de las Comunidades Europeas (2002). Corporate Social Responsibility: A Business Contribution to Sustainable Development. COM (2002) 347 final. Bruselas: Comisión Europea. (https://goo. $\mathrm{gl} / 9 \mathrm{SHoKM})(22-06-2018)$.

Comisión de las Comunidades Europeas (2011). Estrategia renovada de la UE para 2011-2014 sobre la responsabilidad social de las empresas. (https://goo.gl/qdLr7E) (26-06-2018).

Crespo, R. (2009). La responsabilidad social empresaria (RSE) a la luz de la Caritas in veritate. Cultura Económica, 75/76, 121-127.

Crivelli, L. (2003). Cuando el homo oeconomicus se convierte en reciprocans. En L. Bruni., \& S. Zamagni (Ed.), Persona y comunión (pp. 29-56). Buenos Aires: Ciudad Nueva.

Dahlsrud, A. (2008). How Corporate Social Responsibility is defined: An Analysis of 37 Definitions. Corporate Social Responsibility and Environmental Management, 15, 1-13. https://doi: 10.1002/ csr. 132

Davis, K. (1967, Winter). Understanding the social responsibility puzzle: What does the businessman owe to society? Business Horizons, 10(4), 45-50. https://doi.org/10.1016/00076813(67)90007-9

Davis, K., \& Blomstrom, R. L. (1966). Business and its environment. New York: McGraw- Hill.

Eilbert, H., \& Parket, I. R. (1973). The current status of corporate social responsibility. Business Horizons, 16(4), 5-14. https://doi.org/10.1016/0007-6813(73)90043-8

Epstein, E. (2006).The 'Good Company'Rhetoric or reality? Corporate Social Responsibility and business Ethics Redux. Berkeley: University of California.

Evan, W. \& Freeman, E. (1993). A Stakeholder Theory of the Modern Corporation: A Kantian Analysis. En Tom L. Beauchamp y Norman E. Bowie (Ed.), Ethical Theory and Business (pp. 75-84). New Jersey: Prentice Hall.

Fehr, E., \& Gachter, S. (2000). Fairness and Retaliation: the Economics of Reciprocity. Journal of Economic Perspectives, 14(3), 159-181. http://dx.doi.org/ 10.1257/jep.14.3.159.

Fitch, H. G. (1976). Achieving corporate social responsibility. Academy of Management Review, 1(1), 38-46. https://doi.org/10.5465/amr.1976.4408754.

Frederick, W., Post, J., \& Davis, K. E. (1992). Business and Society. Corporate Strategy, Public Policy, Ethics, 7th ed. McGraw-Hill: London

Friedman, C. (1970). The social responsibility of business is to increase its profits. Times Magazine, September 13, 122-126. https://goo.gl/thJnWV (26 -06-2018).

Garriga, E., \& Melé, D. (2004). Corporate social responsibility theories: Mapping the territory. Journal of Business Ethics, 53 (1), 51-71. https://doi.org/10.1023/B:BUSI.0000039399.90587.34. 
Groppa, O. (2014). ¿En qué sentido puede ser la reciprocidad una categoría económica? En: Groppa, O. y Hoevel, C. (2009). Hacia el paradigma del don. Cultura Económica, 75/76, 83-96.

Hopkins, M. (1998). The Planetary Bargain: Corporate Social Responsibility Comes of Age. Macmillan: London. ISO (2011). Guía de Responsabilidad Social (ISO 26.0000:2012, IDT). Montevideo: UNIT.

Johnson, H. L. (1971). Business in contemporary society: Framework and issues. Belmont, CA: Wadsworth Pub. Co.

Jones, T. M. (1980). Corporate social responsibility revisited, redefined. California Management Review,22(3), 59-67. http://dx.doi.org/ 10.2307/41164877

Juan Pablo II (1998). Centesimus Annus. Buenos Aires: Ediciones Paulinas.

Matten, D., Crane, A., \& Chappel, W. (2003). Behind the Mask: Revealing the True Face of Corporate Citizenship. Journal of Business Ethics 45(1-2), 109-120. https://doi.or$\mathrm{g} / 10.1023 / \mathrm{A}: 1024128730308$

McGuire, J. W. (1963). Business and society. New York: McGraw-Hill.

Peter, F. (2004). Choice, consent and the legitimacy of market transactions. Economics and Philosophy, 20(1), 1-18. https://doi.org/10.1017/S0266267104001233

Porter, M., \& Kramer M. (2011). Valor compartido. Cómo reinventar el capitalismo y crear una oleada de innovación y crecimiento. Harvard Business Review, (89)1, 31-49. Edición América Latina.

Prahalad, C. K., \& Hart, S.L. (2002). The Fortune at the bottom of the pyramid. Strategy + Business, 26, 2-14.

Steinberg, E. (2000). Just Business Ethics in Action. Oxford: Oxford University Press.

Van Marrewijk, M. (2001). The Concept and Definition of Corporate Social Responsibility. Amsterdam: Triple P Performance Center.

WBCSD (1999). Corporate Social Responsibility: Meeting Changing Expectations. Geneva: World Business Council for Sustainable Development.

WBCSD (2000). Corporate Social Responsibility: Making Good Business Sense. Geneva: World Business Council for Sustainable Development.

Wymer, W., \& Rundle-thiele, S. R. (2017). Inclusion of ethics, social responsibility, and sustainability in business school curricula : a benchmark study. International Review of Public and Nonprofit Marketing, 14(1), 19-34. https://doi.org/10.1007/s12208-016-0153-z

Zamagni, S. (2006). Heterogeneidad motivacional y comportamiento económico: La perspectiva de la economía civil. Madrid: Unión Editorial.

Zamagni, S. (2007). El bien común en la sociedad posmoderna: Propuestas para la acción político-económica. Cultura Económica, 70, 23-43.

Zamagni, S. (2009). Fraternidad, don y reciprocidad en la Caritas in Veritae. Cultura Económica, 75/76, 11-29.

Zamagni, S. (2012). Por una economía del bien común. Madrid: Ciudad Nueva.

Zenisek, T. J. (1979). Corporate social responsibility: A conceptualization based on organizational literature. Academy of Management Review, 4(3), 359-368. https://doi.org/10.5465/ amr.1979.4289095. 